\title{
MEDICINA FORENSE EN IMÁGENES
}

\section{Figuras de Lichtenberg en un caso de muerte por fulguración.}

Figures of Lichtenberg in a case of death from lightning.

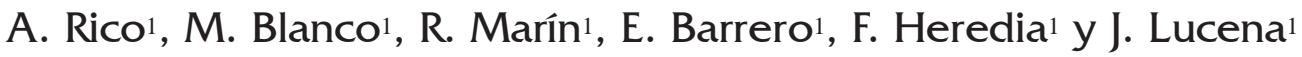

\section{RESUMEN}

Se expone un caso de muerte por fulguración, en el cual están representadas una gran parte de las lesiones y hallazgos que se pueden encontrar en las víctimas que sufren este tipo de accidente. Se hace hincapié en las inusuales figuras arboriformes o en helecho, patognomónicas de la acción del rayo sobre el cuerpo (Figuras de Lichtenberg). Se describen y discuten dichas lesiones, los mecanismos de muerte en este tipo de accidentes y los distintos problemas médico-forenses que se plantean.

Palabras clave: Figuras de Lichtenberg, fulguración, medicina forense.

\section{ABSTRACT}

A case of death from lightning is presented in which they are represented a great part of the lesions and findings that can be seen in the victims that suffer this type of accident. Stress is made on the unusual fern-like aboresque pattern that is typical of the action of the ray on the body (figures of Lichtenberg). These lesions are described and discussed as well as the mechanisms of death in this type of accidents and the different medico-legal problems established.

Key words: Figures of Lichtenberg, lightning, forensic medicine.

Correspondencia: Antonio Rico García. Servicio de Patología Forense. Instituto de Medicina Legal de Sevilla. Avda. Sánchez Pizjuán s/n. 41071 Sevilla. e-mail: iaf.sevilla@andaluciajunta.es.

1 Servicio de Patología Forense. Instituto de Medicina Legal de Sevilla. 


\section{INTRODUCCIÓN:}

Las muertes como consecuencia de la acción del rayo en nuestro medio son poco frecuentes. Para Knight [I], se trata de una causa de muerte frecuente en países tropicales y subtropicales. Sin embargo, en EEUU, las lesiones por fulguración afectan de 800 a 1000 personas por año [2]; entre 1985 y 1995 murieron como consecuencia de la fulguración 1318 personas en dicho país, causando más muertes que cualquier otra catástrofe natural, como por ejemplo huracanes y tornados [3]. En países mediterráneos, donde son frecuentes las tormentas y los trabajos a la intemperie, la frecuencia viene a ser de I-2/I000000 y año [4]. Actividades profesionales como el pastoreo o la agricultura, así como las actividades deportivas de montaña son las más predispuestas a que los individuos que la practican sufran accidentes por fulguración. El efecto físico de la fulguración es complejo y no bien comprendido. Se producen enormes descargas eléctricas sobre el terreno dotadas de altísimo voltaje y amperaje [I], lo cual provoca al ser humano, cuando le afecta, gravísimas lesiones o la muerte.

\section{PRESENTACIÓN DEL CASO:}

ANTECEDENTES:

Los hechos tuvieron lugar durante la primavera, coincidiendo con unos días en los que se produjeron numerosas tormentas. La víctima era un joven de 25 años de edad, dedicado a las labores agrícolas, que se encontraba recogiendo espárragos junto a un numeroso grupo de recolectores. Según relatan los supervivientes, se produjo un intenso resplandor acompañado de una fuerza que les lanzó por el suelo, quedando momentáneamente aturdidos. Repuestos del golpe observaron que uno de sus compañeros yacía inerte en el suelo; le trasladaron al Centro de Salud más cercano donde ingresó ya cadáver. El resto de afectados no sufrió ningún tipo de lesiones.

\section{HALLAZGOS DE AUTOPSIA:}

a) Ropas: Los pantalones y la ropa interior con la que se vestía presentaba varios desgarros (Fig. $n^{\circ} \mathrm{I}$ ), destacando una leve imantación de los botones metálicos del pantalón.

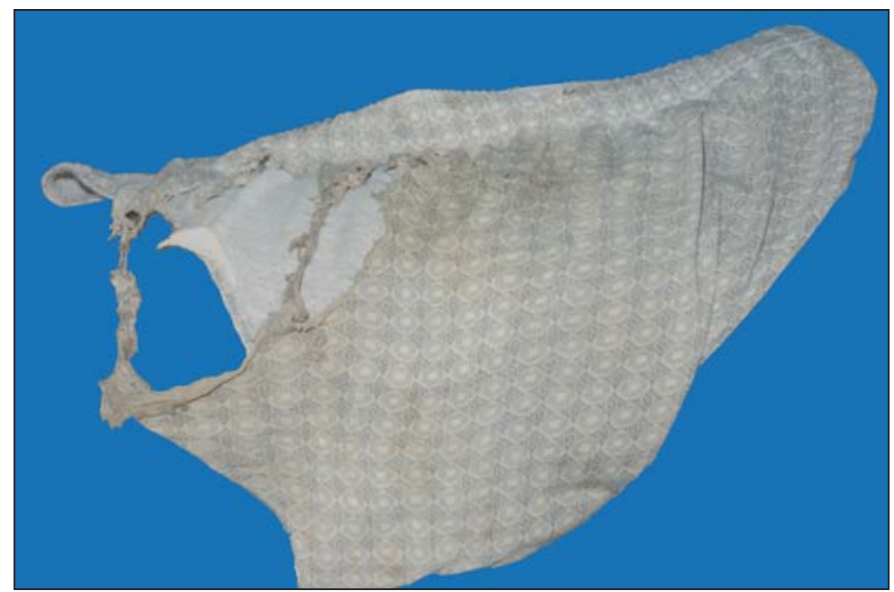

Figura $\mathbf{n}^{\circ}$ 1.- Estallido de las ropas

b) Examen externo del cadáver:

Se trataba de un varón de $170 \mathrm{~cm}$ de estatura y un peso de $80 \mathrm{~kg}$. Destacaban las siguientes lesiones: 
- Múltiples quemaduras de morfología puntiforme y semilunar, en pabellón auricular derecho y región laterocervical del mismo lado; observándose chamuscamiento del cabello de la región temporal y parietal derecha. (Fig. n²).

- Extensas quemaduras superficiales, con desprendimiento de la epidermis, localizadas en la cara posterior del cuello y la mitad superior de la espalda (Fig. n 3), así como en región glútea y cara posterior del miembro inferior izquierdo (Fig. $n^{\circ} 4$ ).

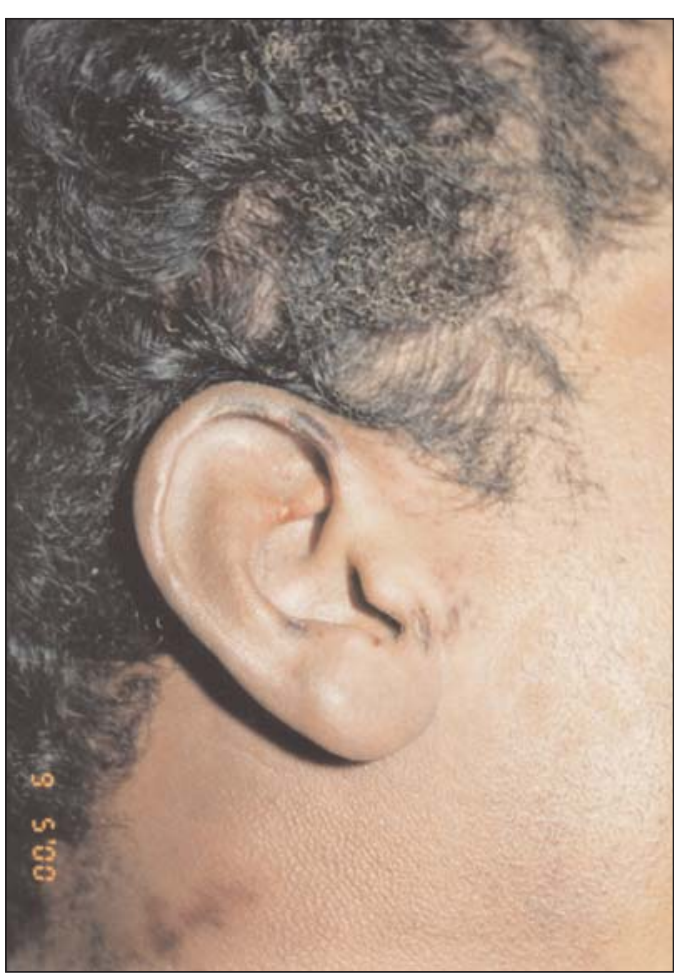

Figura $\mathbf{n}^{\circ}$ 2.- Quemaduras en pabellón auricular y chamuscamiento de cabellos.

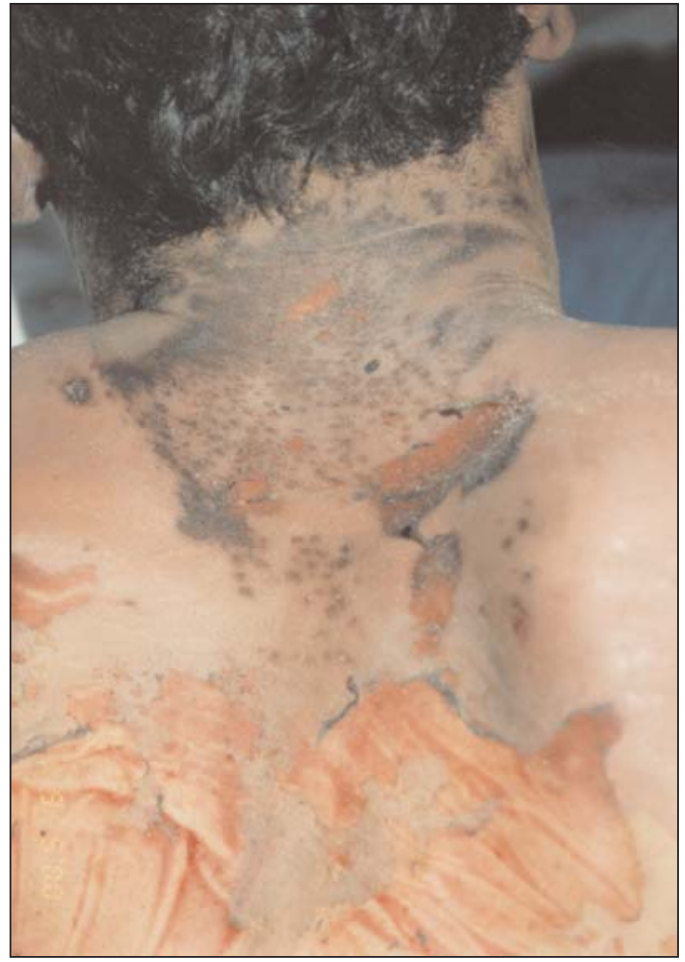

Figura $n^{\circ}$ 3.- Quemaduras en la cara posterior del cuello y espalda.

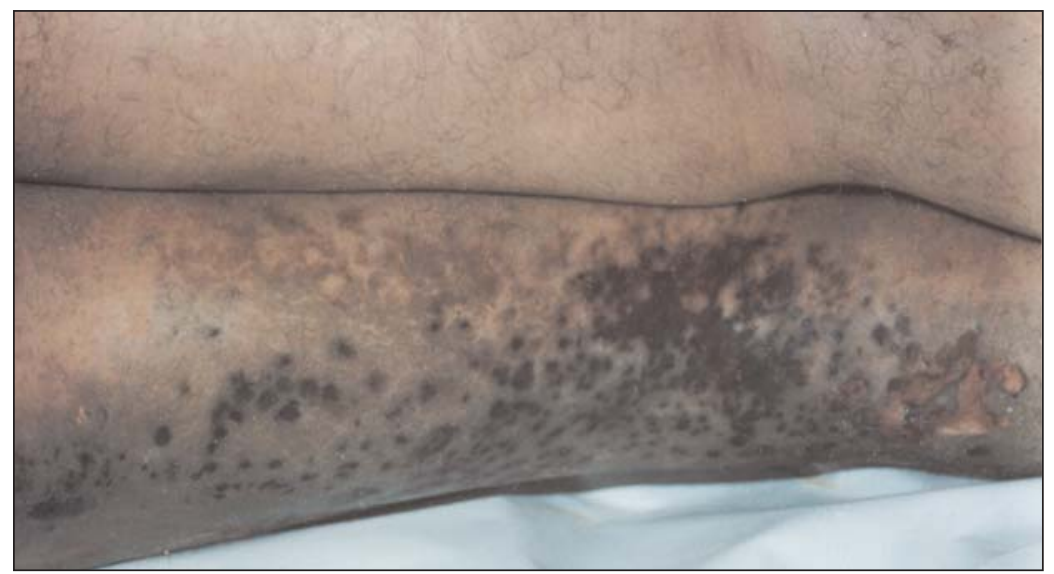

Figura $\mathrm{n}^{\circ}$ 4.- Quemaduras en cara posterior de miembro inferior izquierdo. 
- Lesiones cutáneas de aspecto arboriforme, en helecho, localizadas en la cara anterior del tronco y flanco izquierdo (Figs. $n^{\circ} 5$ y 6 ), codo derecho y rodilla izquierda.
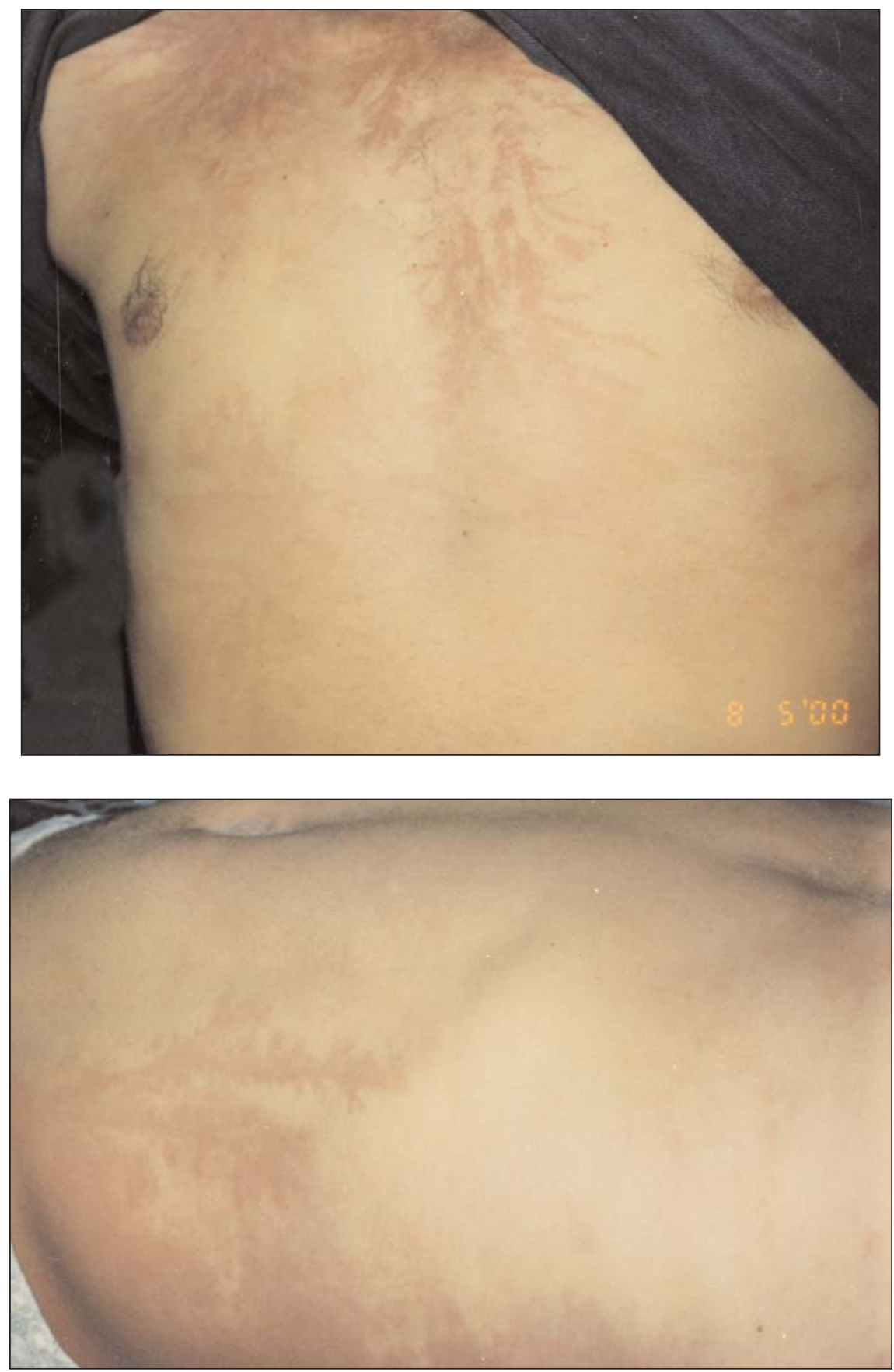

Figuras $\mathbf{n}^{\circ} 5$ y 6.- Figuras de Lichtenberg. 


\section{c) Examen interno:}

En el examen interno destacaban los siguientes hallazgos:

- Intensa congestión encefálica superficial, así como al corte del parénquima, no observándose alteraciones estructurales en los cortes coronales practicados. El encéfalo pesaba $1340 \mathrm{~g}$.

- El corazón pesaba 400 g y se observaba la presencia de equimosis subepicárdicas en la cara anterior del ventrículo derecho.

- Congestión vascular generalizada, sin otros hallazgos.

\section{EX'ÁMENES COMPLEMENTARIOS:}

Se enviaron muestras al Instituto Nacional de Toxicología de Sevilla para:

1. Análisis Toxicológico de sangre: no se detectó ninguna sustancia tóxica o psicoactiva.

2. Examen histopatológico: únicamente destacar congestión vascular encefálica y edema.

\section{DISCUSIÓN:}

Cuando existen testigos, antecedentes de tormentas con gran aparato eléctrico, los casos de muerte por fulguración no suelen plantear graves problemas médico-forenses, sin embargo, es muy frecuente que se trate de personas que se encuentran solas en el campo realizando sus actividades laborales (pastores, agricultores) o conduciendo bicicletas o motocicletas, lo cual da lugar a distintas hipótesis con respecto al tipo y causa de la muerte. También se dan casos especiales, recogidos por la literatura médico-forense, por lo "extraño" de los accidentes que puede provocar el rayo, como son muertes por fulguración en personas que se encuentran en la cama dentro de su domicilio [5], o el alcance de un rayo a una persona dentro de un estadio atestado de personas mientras hablaba por su teléfono móvil, sin que otras personas fueran afectadas [6].

Cuando el rayo afecta al ser humano le produce gravísimas lesiones o la muerte, fundamentalmente por afectación cardíaca, siendo esta la principal causa de muerte [2], generalmente secundaria a fibrilación ventricular. Están descritas lesiones isquémicas en forma de infarto agudo de miocardio severo tras la fulguración [7]. También son causa de muerte la afectación directa de los centros nerviosos, con parálisis respiratoria o por los efectos mecánicos de la fulguración sobre el organismo [4].

En el cadáver vamos a encontrar una serie de hallazgos y lesiones que nos orientaran el diagnóstico. Gisbert [4] hace mención a las lesiones electromecánicas, que pueden ser:

- Heridas contusas con sufusiones hemorrágicas alrededor, y quemaduras y chamuscamiento de los pelos que pueden confundirse con heridas por arma de fuego.

- En otros casos pueden simular limpias heridas incisas, punzantes, incisopunzantes o cortantes, y también adoptar la forma anfractuosa de las heridas contusas.

Di Maio [8] describe como fundamentales los siguientes:

- Daños en las ropas, como grandes desgarros, rupturas, chamuscamiento, pudiendo estar literalmente arrancada o desgarrada. La escena puede producir la falsa impresión de una muerte tras una violación o una agresión, si no se reconoce rápidamente la verdadera naturaleza de la situación.

- Chamusca el pelo de todo el cuerpo o parte del mismo.

- Quemaduras en la piel que se encuentra en contacto con un objeto metálico, como joyas, hebillas, cinturones o cremalleras. 
- Ruptura timpánica, con flujo de sangre por los conductos auditivos externos. Esto puede ser malinterpretado como un traumatismo craneal. Algunos autores estiman que la ruptura timpánica se produce en más del $80 \%$ de los casos [9].

- Magnetización de objetos de hierro o acero que se encuentran en los bolsillos de la víctima.

- Las quemaduras externas son muy variables. Pueden existir quemaduras en forma de arco en descargas directas o impactos secundarios.

Mención especial merecen las lesiones en helecho o arboriformes, signo patognomónico de la fulguración [9]; cuyo patrón morfológico fue descrito en 1777 por el físico alemán George Christoph Lichtenberg, del cual han tomado su nombre [I]. Se describe como una marca roja, dendrítica, ramificada, similar a un helecho, que se encuentra en la piel de algunas de las víctimas [10]; y que encontraremos en un tercio de los casos. Hay numerosas teorías que intentan explicar el origen de esta lesión, pero la causa real es todavía desconocida [8]. Algunos autores [4] establecen como hipótesis que se trataría de dilataciones vasculares paralíticas en los lugares correspondientes a los puntos de paso de la corriente.

\section{CONCLUSIONES:}

Si bien la fulguración es una causa de muerte infrecuente en nuestro medio, es de suma importancia conocer cuales son los hallazgos fundamentales en el cadáver, insistiendo en las Figuras de Lichtenberg, imágenes patognomónicas de la acción del rayo, con el fin de hacer el diagnóstico diferencial con muertes homicidas u otro tipo de muertes accidentales.

\section{BIBLIOGRAFÍA:}

I.- Saukko P, Knight B: KNIGHT'S Forensic Pathology. $3^{\text {a }}$ ed. Editorial ARNOLD. Londres, 2004. 326-338.

2.- Cooper MA: Emergent care of lightning and electrical injures. Semin Neurol. 1995; 15 (3): 268-78.

3.- Lightning-associated deaths-United States, 1980-1995: MMWR Morb Mortal Wkly Rep 1998; 47 (19): 39I-4.

4.- Castellano M: Lesiones por agentes físicos. En: Gisbert JA. 9.- Wetli CV: Keraunopathology. An analysis of 45 fatalities. Am J Medicina Legal y Toxicología. $6^{\text {a }}$ ed. Editorial MASSON. Barcelona, 2004. pp 409-430.

5.- Blanco-Pampin JM, Peñaranda JM, Boquete RR, Carro LC: An unu-

6.- Milizman DP, Moskowitz L, Hardel M: Lightning strikes at a mass gathering. South Med J 1999; 92 (7): 708-10.

7.- Zack F, Hammer U, Klett I, Wegener R: Myocardial injury due to ligtning. Int J Legal Med 1997; IIO (6): 326-8.

8.- Di Maio V, Dana S: Manual de Patología Forense. Editorial Díaz de Santos, S.A., Madrid 2003. 202-205.

Forensic Med Pathol 1996; 17 (2): 89-98.

10.- Resnik BI, Wetli CV: Lichtenberg figures. Am J Forensic Med sual case of death by lightning. J Forensic Sci 1997; 42 (5): 942-4. 